\title{
Evaluation of polymer modified asphalts containing warm mix additives in rheology
}

\author{
H.-S. Kim ${ }^{1}$, S.-J. Lee ${ }^{2}$, S. N. Amirkhanian ${ }^{1}$ \& T.-S. Park ${ }^{3}$ \\ ${ }^{1}$ Department of Civil Engineering, Clemson University, USA \\ ${ }^{2}$ Department of Technology, Texas State University-San Marcos, USA \\ ${ }^{3}$ Department of Civil Engineering, \\ Seoul National University of Technology, South Korea
}

\begin{abstract}
Polymer modified asphalt (PMA) binders can be utilized using warm mix asphalt (WMA) technologies in order to aim for the green highway construction by lowering construction temperatures and toxic by-products (i.e., $\mathrm{CO}_{2}$, smoke, and odor). This paper focused on a rheological investigation of three PMA binders, graded as PG 76-22, containing two warm additives (Aspha-min ${ }^{\mathbb{B}}$ and Sasobit ${ }^{\mathbb{B}}$ ) available commercially. The main rheological factors selected in this study were relationships between loading and response as a function of time, temperature and frequency using a Bohlin Dynamic Shear Rheometer II. The results suggested that the two warm additives positively influenced the performance of PMA binders. In particular, the use of Sasobit ${ }^{\circledR}$ showed the enhanced rutting resistance properties at high pavement temperature and more elastic properties at lower temperatures.

Keywords: PMA binders, WMA, rheology.
\end{abstract}

\section{Introduction}

Warm mix asphalt (WMA) technologies are progressing very rapidly, emphasizing the reduction of mixing and compaction temperature of hot mix asphalt (HMA) in road construction. With this innovation, it is anticipated to decrease temperatures to as much as $100^{\circ} \mathrm{F}\left(37^{\circ} \mathrm{C}\right)$ without compromising the performance of the asphalt pavement. In practice, successful results have been reported from Europe, South Africa, Asia, and the United States [1-2]. 
Polymer modified asphalt (PMA) binders are increasingly becoming more important components of asphalt production due to their superior performance in improving resistance to rutting, fatigue damage, stripping, thermal cracking and temperature susceptibility [3]. However, PMA binders require high temperatures for mixing and compacting than conventional HMA. This might led to negative issues including excessive construction cost, binder aging, and plant emission. By incorporating the warm additives into PMA binders, they are expected to become more fluid at lower temperatures while superior qualities and environmental friendly processes are achieved concurrently.

The objective of this study is to investigate the feasibility of adding the warm mix additives in PMA binders using a rheological tool, with emphasis on relationships between shear stress (loading) and strain (response) at given conditions.

\section{Experimental program}

\subsection{Materials}

Three PMA binders, graded as PG 76-22, were used in this study. Origins of each binder were from a Venezuelan, a local terminal which blends several binder sources, and a Middle Eastern. Table 1 summarizes the basic properties of these binders.

Two different types of warm additives (i.e., Sasobit ${ }^{\circledR}$ and Aspha-Min ${ }^{\circledR}$ ) were evaluated on the PMA binders. Sasobit ${ }^{\circledR}$ is an organic hard wax type produced from coal gasification using Fishcher-Tropsch process. It is completely melted into the asphalt binder at temperature in excess of $240^{\circ} \mathrm{F}\left(115^{\circ} \mathrm{C}\right)$, leading to a

Table 1: $\quad$ Properties of PMA binders.

\begin{tabular}{|l|l|c|c|c|}
\hline \multirow{2}{*}{ Aging states } & \multicolumn{1}{|c|}{ Test properties } & \multicolumn{3}{c|}{ Binder sources } \\
\cline { 3 - 5 } & \multicolumn{1}{|c|}{$\begin{array}{l}\text { Rotational viscosity } \\
\text { at } 135^{\circ} \mathrm{C}(\mathrm{Pa}-\mathrm{s})\end{array}$} & 2.139 & 1.537 & 1.428 \\
\cline { 2 - 5 } Unaged binder & $\mathrm{G}^{*} / \mathrm{sin} \delta$ at $76^{\circ} \mathrm{C}(\mathrm{kPa})$ & 1.702 & 1.382 & 1.163 \\
\hline $\begin{array}{l}\text { RTFO } \\
\text { residual }\end{array}$ & $\mathrm{G}^{*} / \mathrm{sin} \delta$ at $76^{\circ} \mathrm{C}(\mathrm{kPa})$ & 4.498 & 2.579 & 2.558 \\
\hline \multirow{2}{*}{$\begin{array}{l}\mathrm{RTFO}+\mathrm{PAV} \\
\text { residual }\end{array}$} & $\mathrm{G}^{*} \sin \delta$ at $25^{\circ} \mathrm{C}(\mathrm{kPa})$ & 2880 & 4167 & 1775 \\
\cline { 2 - 5 } & $\mathrm{Stiffness}$ at $-12^{\circ} \mathrm{C}(\mathrm{MPa})$ & 133 & 175 & 126 \\
\cline { 2 - 5 } & $\mathrm{m}$-value at $-12^{\circ} \mathrm{C}$ & 0.336 & 0.301 & 0.333 \\
\hline
\end{tabular}


reduction of the binder viscosity [4]. Aspha- $\operatorname{Min}^{\circledR}$ is a mineral powder type (i.e., synthetically manufactured zeolite) containing roughly $20 \%$ water of crystallization by weight. A foaming action ensures a slight increase in the binder volume, enabling the asphalt mix to be more workable at lower temperature [5].

\subsection{Procedures}

The flowchart of the experimental procedures is shown in Figure 1. The warm PMA binders were produced by two different processes. Process 1 involved the addition of Aspha-min ${ }^{\circledR}$ with manual blending. The concentration was used at $5 \%$ by binder weight recommended by the manufacture. It was added into the PMA binder, heated at $150^{\circ} \mathrm{C}$ and followed by blending with stirrer to disperse thoroughly. Process 2 involved the addition of Sasobit ${ }^{\circledR}$ with mechanical blending. Approximately $1.5 \%$ by binder weight was added into the PMA binder and followed by blending with mechanical mixer at $150^{\circ} \mathrm{C}$ for 5 minutes [6].

Rheological analyses including a flow behavior, creep loading and response, frequency dependence test within the linear viscoelastic region were conducted at $60^{\circ} \mathrm{C}$ using a Bohlin Dynamic Shear Rheometer II having a $25 \mathrm{~mm}$ diameter plate-plate geometry and a $1 \mathrm{~mm}$ gap. In addition, a temperature dependence test was conducted between the temperatures of $25^{\circ} \mathrm{C}$ and $80^{\circ} \mathrm{C}$ at a frequency of $1.59 \mathrm{~Hz}$.

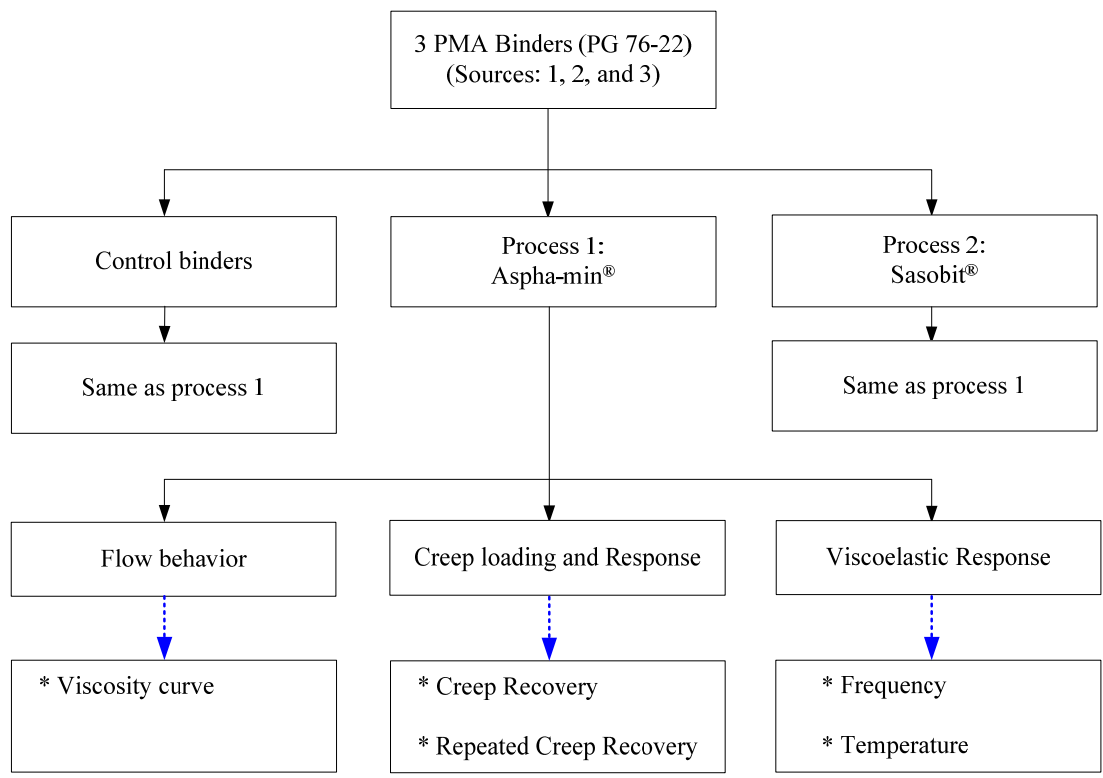

Figure 1: Flow chart of experimental procedures. 


\section{Results}

\subsection{Flow behavior}

Figure 2 shows the relationship between shear rate and viscosity for second source of PMA binders for all combinations (i.e., Aspha-min ${ }^{\circledR}$ (A), $\operatorname{Sasobit}^{\circledR}$ (S) and Control (binder without additive)). The curves show Pseudo-plastic behavior which mainly occurs in modified asphalts because the viscosity decreases with the increase in the shear rate from a certain point [7]. The viscosity noticeably dropped around the shear rate of $10^{-1} / \mathrm{sec}$ with similar tendency for all binder types. In particular, Sasobit ${ }^{\circledR}$ increased the viscosity of the PMA binder, while Aspha-min ${ }^{\circledR}$ seemed to have little influence in the viscosity at the test temperature of $60^{\circ} \mathrm{C}$. In other words, Sasobit ${ }^{\circledR}$ improves flow resistance of the PMA binder at a critical pavement temperature which can enhance rutting performance.

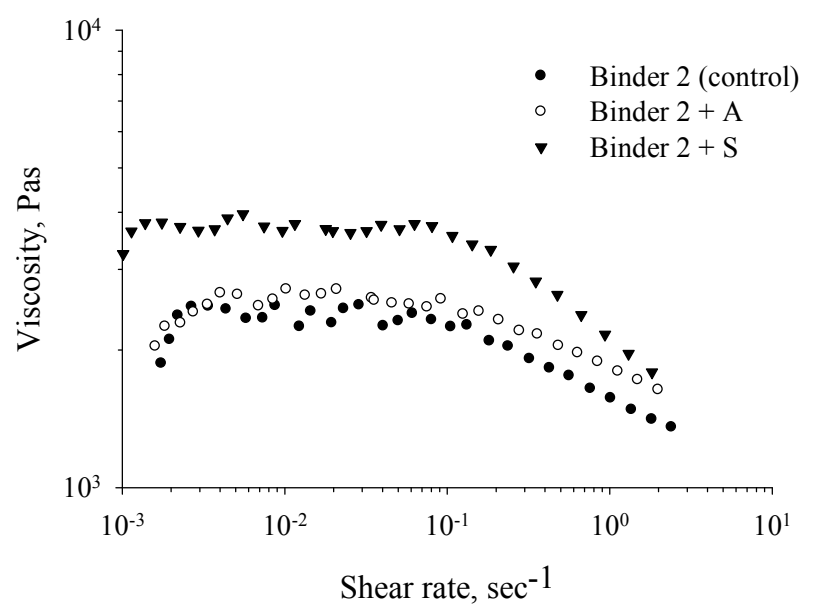

Figure 2: $\quad$ Flow curves for binder 2 for all combinations (control, + Aspha$\min ^{\circledR},+$ Sasobit $\left.^{\circledR}\right)$.

\subsection{Creep loading and response}

For the creep loading and response behavior of the binders, a creep recovery test and a repeated creep recovery test were performed. In a creep recovery test, the strain is monitored even after the applied stress is removed, giving an indication of the amount of non-recoverable strain or permanent deformation. In this study, $10 \mathrm{~Pa}$ of stress level (loading for $20 \mathrm{sec}$. and $600 \mathrm{sec}$. recovery) was applied to represent the medium stress levels of traffic on the asphalt pavement.

The repeated creep recovery test simulates traffic passing on a pavement since it first applies a stress for a short period of time, then leaves the material to recover for a longer period of time, and repeats this cycle for a number of times 


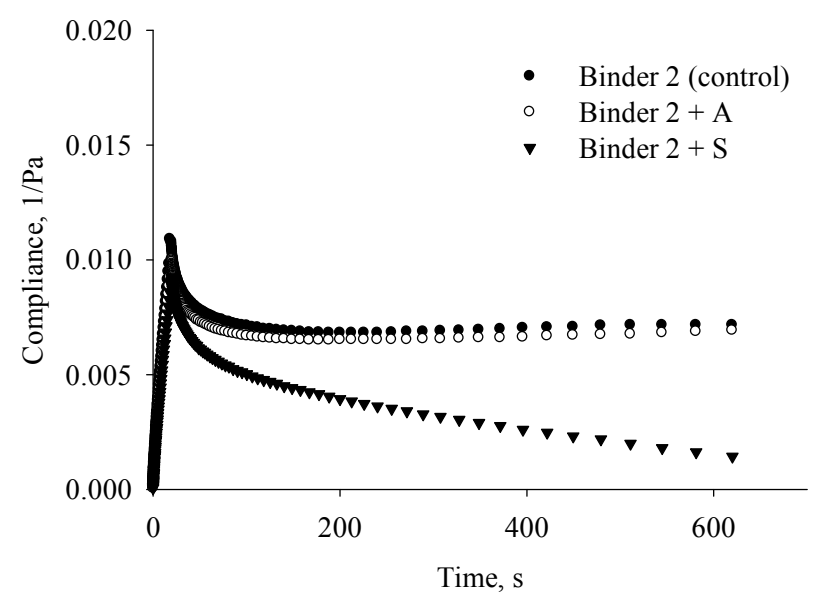

(a)

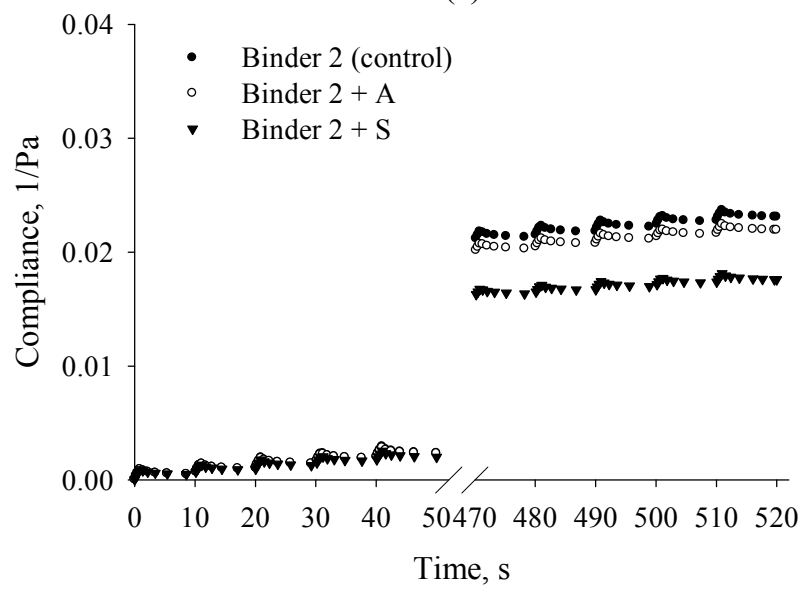

(b)

Figure 3: $\quad$ Creep loading and response curves (a) creep recovery (b) repeated creep recovery for binder 2 for all combinations (control, + Aspha$\min ^{\circledR},+$ Sasobit $\left.^{\circledR}\right)$.

[8]. The test process in this study, which followed NCHRP Report 459 [9], consisted of 52 cycles of loading with a stress of $10 \mathrm{~Pa}$ for $1 \mathrm{sec}$ and recovery for $9 \mathrm{sec}$.

Figure 3 shows creep loading and response curves for second source of PMA binders for all combinations. The addition of the warm mix additives was observed to lower the compliance values in both of test conditions and the binder with Sasobit ${ }^{\circledR}$ particularly showed the least values. These observations suggest that the addition of the warm mix additives makes the PMA binders more resistant to permanent deformation at service temperature. Comparatively, Sasobit $^{\circledR}$ was more effective than Aspha-min ${ }^{\circledR}$. This trend was also observed for other binder sources. 


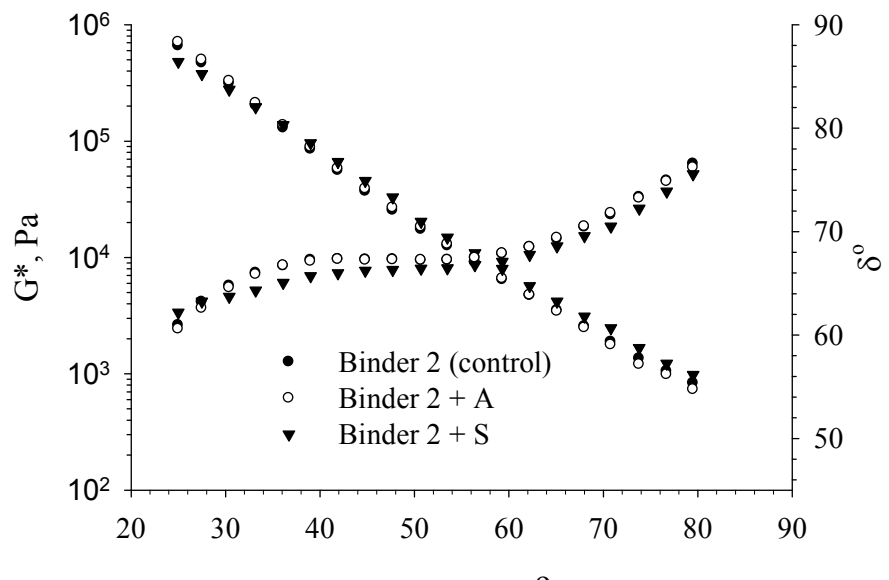

Temperature, ${ }^{\circ} \mathrm{C}$

(a)

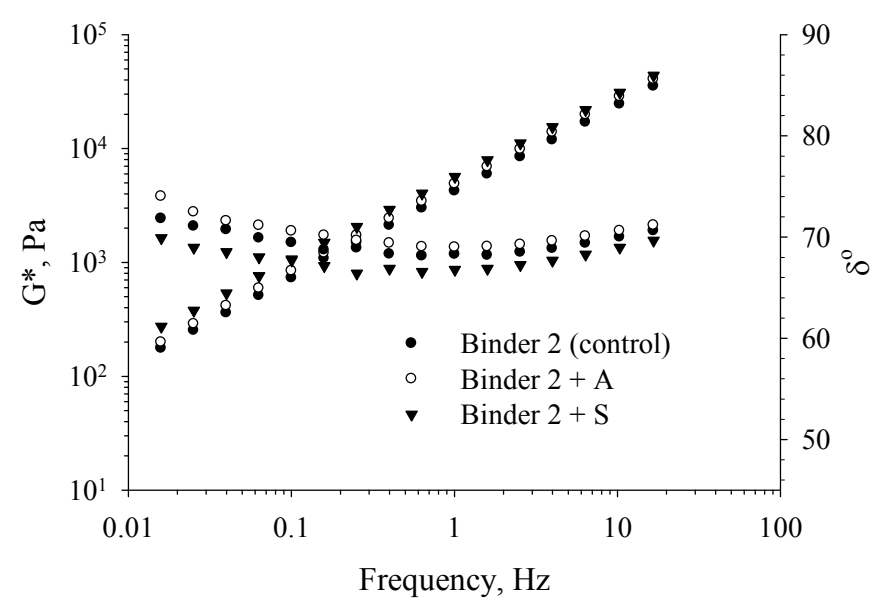

(b)

Figure 4: Viscoelastic response curves (a) temperature (b) frequency dependence for binder 2 for all combinations (control, + Aspha$\min ^{\mathbb{B}},+$ Sasobit $\left.^{\mathbb{R}}\right)$.

\subsection{Viscoelastic response}

Asphalt rheology can be categorized by two main viscoelastic parameters including complex modulus $\left(\mathrm{G}^{*}\right)$ and the phase angle $(\delta)$. These parameters change with temperature and loading time. Complex modulus represents stiffness, which is a measure of the overall resistance to deformation of the sample tested and phase angle is used as a symbol of viscous or elastic behavior. 
Especially, higher values of phase angle indicate a tendency towards more viscous behavior, while lower values indicate more elastic behavior [10].

Figure 4 shows viscoelastic response curves for PMA binder source 2 for all combinations. The results of the temperature dependence (Figure 4 a) indicate that the addition of the warm mix additives did not seem to change the complex modulus of the binders through the range of temperatures. However, the phase angle tended to have lower values at lower temperatures in case of the addition of Sasobit ${ }^{\mathbb{R}}$. The frequency curve (Figure 4: b) showed that no significant change for the complex modulus with the addition of the warm additives into the PMA binder through the range of frequencies. However, the addition of Sasobit ${ }^{\circledR}$ seemed to decrease the phase angle values, especially at lower frequencies of loading. The trends were the same for other binder sources.

\section{Conclusions}

(1) The flow property showed that the warm mix additives did not negatively affected the polymer structure and rather adapted into the PMA binder network.

(2) The PMA binders containing Sasobit ${ }^{\mathbb{B}}$ were found to have better rutting resistance, based on less flow (higher viscosity or stiffer) at $60^{\circ} \mathrm{C}$, at the high temperature of flexible pavement.

(3) From the characteristics of creep loading and response, the addition of the warm additives was observed to enhance the rutting resistance of binders at high temperatures.

(4) The viscoelastic response test indicated that the addition of the warm mix additives to the PMA binders did not significantly change the complex modulus for the entire range of the test temperatures and frequencies. However, the PMA binders with Sasobit ${ }^{\circledR}$ seemed to lower the phase angle at lower temperatures and frequencies, indicating an improved elastic behavior.

\section{Acknowledgement}

The authors wish to acknowledge and thank South Carolina's Department of Health and Environmental Control (DHEC) for their financial support of this project.

\section{References}

[1] Jones, W. (2004). Warm Mix Asphalt Pavement, Asphalt, Fall, pp. 8-11.

[2] Tomlinson Times. (2007), Sasobit Warm Mix Asphalt Technology, Internal Newsletter of R.W. Tomlinson Limited, Winter, pp. 2-3.

[3] Wekumbura, C., Stastna, J., and Zanzotto, L. (2007), Destruction and Recovery of Internal Structure in Polymer-Modified Asphalts, Journal of Materials in Civil Engineering, pp 227-232.

[4] Sasol Wax. Accessed from http://www.sasolwax.com/Sasobit ${ }^{\circledR}$ Technology.html. 
[5] Eurova Services. Accessed from http://www.eurovia.com/en/produit/ 135.aspx.

[6] Gandhi, T., Amirkhanian, S. (2007), Laboratory Investigation of Warm Asphalt Binder Properties - A Preliminary Investigation, MAIREPAV 5 Proceedings, Vol. 5, 2007, pp. 475-480, Park City, Utah.

[7] Asphalt Institute. (2003), Performance Graded Asphalt Binder Specification and Testing, Superpave Series No. 1 (SP-1), pp. 8-9.

[8] Binard, C., Anderson, D., Lapalu, L., and Planche, J.P. (2004), Zero shear viscosity of modified and unmodified binders, $3^{\text {rd }}$ Euraphalt \& Eurobitume Congress, Vienna, Austria, Book II, pp. 1721-1733.

[9] Bahia, H.U., Hanson, D.I, Zeng, M., Zhai, H., Khatri, M.A., and Anderson RM. (2001), Characterization of Modified Asphalt Binder in Superpave Mix Design, NCHRP Report 459.

[10] Widyatmoko, I., and Elliott, I. (2008), Characteristics of elastomeric and plastomeric binders in contact with natural asphalts, Construction and Building Materials 22, pp. 239-240. 